\title{
Antimalarial Activity of Stem Bark of Periploca linearifolia during Early and Established Plasmodium Infection in Mice
}

\author{
Wubetu Yihunie Belay, ${ }^{1}$ Abyot Endale Gurmu $\mathbb{D}{ }^{2},{ }^{2}$ and Zewdu Birhanu Wubneh $\mathbb{D}^{3}$ \\ ${ }^{1}$ Department of Pharmacy, Debre Markos Referral Hospital, Debre Markos, Ethiopia \\ ${ }^{2}$ Department of Pharmacognosy, School of Pharmacy, University of Gondar, Gondar, Ethiopia \\ ${ }^{3}$ Department of Pharmacology, School of Pharmacy, University of Gondar, Gondar, Ethiopia \\ Correspondence should be addressed to Zewdu Birhanu Wubneh; zbirhanu@gmail.com
}

Received 7 September 2017; Revised 25 October 2017; Accepted 29 November 2017; Published 29 January 2018

Academic Editor: Juntra Karbwang

Copyright (C) 2018 Wubetu Yihunie Belay et al. This is an open access article distributed under the Creative Commons Attribution License, which permits unrestricted use, distribution, and reproduction in any medium, provided the original work is properly cited.

\begin{abstract}
Background. In Ethiopia, stem bark of Periploca linearifolia is used for the treatment of malaria by the local community and demonstrated antimalarial activity in vitro. Despite its in vitro antimalarial activity, no scientific study has been carried out to verify its activity in vivo. Therefore, the aim of the study was to evaluate the antimalarial activity of Periploca linearifolia stem bark extract in mice. Methods. The dried stem bark of Periploca linearifolia was extracted with $80 \%$ methanol and evaluated for its antimalarial activity on both early and established Plasmodium berghei infected mice. The extract was prepared at graded doses of 200, 400, and $600 \mathrm{mg} / \mathrm{kg}$. Chloroquine and distilled water were administered to the positive and negative control groups, respectively. Results. The crude extract, at all tested doses, suppressed parasitemia significantly $(p<0.05)$ for 200 and $400 \mathrm{mg} / \mathrm{kg}$ and $(p<0.001)$ for $600 \mathrm{mg} / \mathrm{kg}$. The suppression values at these doses were 56.98, 43.33, and 38.17 percent, respectively. Periploca linearifolia extract also demonstrated schizonticidal activity in the established malaria infection. Conclusion. The plant Periploca linearifolia has a promising antimalarial activity in mice, supporting its in vitro finding. Thus, it could be considered as a potential source to develop new antimalarial agent.
\end{abstract}

\section{Background}

Malaria, among the most frequent infectious diseases worldwide, causes millions of deaths each year globally. The infection mostly affects children below the age of five. Furthermore, about $99 \%$ of the deaths are caused by P. falciparum [1]. Growth and multiplication of the Plasmodium parasite involve both the vector female Anopheles mosquitoes and humans [2]. Malaria in humans is attributable to 5 species of the parasite in the genus Plasmodium. These are P. falciparum, $P$. vivax, $P$. malariae, $P$. ovale, and $P$. knowlesi $[3,4]$.

Currently, malaria control is threatened not only by the development of mosquitoes resistant to the available insecticides but also by the currently existing antimalarial agents [1]. Developing antimalarial vaccine is very complex due to antigenic nature of the parasite, its ability to present a different subset of molecules for the immune system, the parasites ability to confuse, hide, and misdirect our immune system, and the possibility of having several plasmodial infections of not only different species but also different strains at the same time [5]. With remarkable efforts, a new antimalarial vaccine candidate RTS,S/AS01 has completed its phase III clinical trial successfully and will be available in Ghana, Malawi, and Kenya starting from 2018 [6]. Traditional medicine through use of natural products plays a great role in the discovery of antimalarial lead compounds and drug candidates like quinine from cinchona bark [7] and artemisinins from Artemisia annua [8]. Extract from stem bark of P. linearifolia (Asclepiadaceae) demonstrated a promising antiplasmodial activity in vitro [9]. Due to the emergence of antimalarial drug resistance and mosquito's resistance to insecticides, there is a high interest in developing new antimalarial drugs $[1,10]$.

\section{Methods}

2.1. Collection and Preparation of the Plant Material. Stem bark of $P$. linearifolia plant was collected from Lay Armachiho 
Woreda in the vicinity of Tikil Dingay town, North Gondar Zone, $23 \mathrm{~km}$ north of Gondar city in December 2016. The plant was botanically identified by a botanist and a voucher specimen was deposited for future reference at the Herbarium of Biology Department, University of Gondar.

2.2. Animals. Healthy adult Swiss albino mice of either sex (22-32 $\mathrm{g}$ and 6-8 weeks of age) were obtained from the animal house of the School of Pharmacy, College of Medicine and Health Sciences, University of Gondar, Ethiopia. The mice were housed in cages under standard conditions and provided with pellet diet and water ad libitum. The mice were permitted to adapt to the laboratory condition for seven days prior to the beginning of actual experiment. All protocols were performed in accordance with the international animal care and welfare guideline [11]. Indeed, all the experimental procedures were approved by the ethical review board of Department of Pharmacology, School of Pharmacy, University of Gondar.

2.3. Parasite Inoculation. Chloroquine-sensitive $P$. berghei (ANKA strain) was obtained from Ethiopian Public Health Institute, Addis Ababa. The parasite was sustained via sequential passage of blood from infected mouse to noninfected ones on a weekly basis.

2.4. Drugs and Reagents. Normal isotonic saline (EuroMed Laboratories, Philippines), absolute methanol (ReAgent Chemical Services, UK), 2\% tween 80, hydrochloric acid (Blulux Laboratories, India), citrate dextrose (Deluxe Scientific Surgico, India), Giemsa (Science Lab, USA), ethanol (Nice Chemicals, India), ferric chloride (Fisher Scientific, Co., USA), sodium hydroxide, sulfuric acid (Supertech, India), and Mayer's reagent (Avishkar Lab Tech Chemicals, India) were used.

2.5. Extract Preparation. The stem bark was peeled from the plant, air-dried at room temperature under shade, and reduced to appropriate size. A total of $1.2 \mathrm{~kg}$ dried stem bark was extracted by maceration ( $100 \mathrm{~g}$ of dried stem bark in $600 \mathrm{ml}$ of $80 \%$ methanol) for $72 \mathrm{~h}$. The mixture was filtered using gauze followed by Whatman filter paper number 1 (Whatman ${ }^{\circledR}$, England). The residue was remacerated for another 72 hour twice and filtered. The combined filtrates were then put under oven at $40^{\circ} \mathrm{C}$. After evaporating methanol and some part of the aqueous part, it was transferred to a desiccator for further drying. Finally, the dried extract was kept in a vial and stored in a refrigerator at $-4^{\circ} \mathrm{C}$ until use.

\subsection{In Vivo Antimalarial Tests}

2.6.1. Parasite Inoculation. Plasmodium berghei-infected (20-30\% parasitemia) mouse was employed as a donor. The donor mouse was subsequently sacrificed by decapitation and blood collected (via cardiac puncture) into capillary tube containing $0.5 \%$ trisodium citrate. Based on parasitemia level of the donor mouse and the red blood cell (RBC) count of normal mouse, the collected blood was diluted with normal saline $(0.9 \%)$ [12], so that $1 \mathrm{ml}$ blood contains $5 \times 10^{7}$ infected RBCs. Each mouse was injected with $0.2 \mathrm{ml}$ of blood containing $1 \times 10^{7} \mathrm{P}$. berghei-infected RBCs via the intraperitoneal route.

2.6.2. Grouping and Dosing of Animals. Infected mice were arbitrarily divided into five groups of 5 mice per group. Groups I, II, and III were treated with $P$. linearifolia crude extract $(200,400$, and $600 \mathrm{mg} / \mathrm{kg})$, respectively. Groups IV and $\mathrm{V}$ were used as control each for chloroquine $(25 \mathrm{mg} / \mathrm{kg})$ as positive control and distilled water $(2 \mathrm{ml} / 100 \mathrm{~g})$ as negative control, respectively. Doses were selected based on oral acute toxicity studies.

2.6.3. The Four-Day Suppressive Test. In screening of P. linearifolia stem bark extract on an early plasmodium infection, the standard 4-day suppressive test was employed. This test is the most extensively used preliminary test, in which the effectiveness of the extract is evaluated via comparison of blood parasitemia and mouse survival time in extracttreated and untreated mice [13-15]. Treatment was started 3 hours after infection on day 0 and continued daily for four successive days (i.e., from day 0 to day 3). On the fifth day (D4), thin smears of blood were prepared from the tail of each mouse, placed on microscopic slides, fixed in methanol, and Giemsa-stained (10\%) at pH 7.2 for fifteen min. Parasitemia was determined via counting the number of parasitized RBCs in four random microscopic fields. Finally, average percent parasitemia and percent suppression were calculated by using the following formula $[13,14]$ :

$$
\begin{aligned}
& \% \text { parasitemia }=\left(\frac{\text { number of parasitized } \mathrm{RBC}}{\text { total number of } \mathrm{RBC}}\right) \times 100, \\
& \% \text { suppression }=\left(\frac{\text { mean parasitemia of negative control }- \text { mean parasitemia of extract treated group }}{\text { mean parasitemia of negative control }}\right) \times 100 .
\end{aligned}
$$

2.6.4. Evaluation on Established Infection (Rane's Test). The curative effect of the extract was evaluated in accordance with the method described by Ryley and Peters [16]. Standard inocula $\left(1 \times 10^{7}\right)$ of infected RBCs were injected into mice intraperitoneally on day 0 . Seventy-two hours later, mice were randomly distributed into groups and dosed once daily 
for 5 consecutive days. Giemsa-stained thin blood film was prepared from the tail of each mouse daily for 5 days to monitor parasitemia.

2.6.5. Mean Survival Time (MST). MST was determined arithmetically by calculating the average survival time (in days) of mice starting from date of infection with $P$. berghei for a period of thirty days (D0 to D29).

\section{MST}

$$
=\frac{\text { sum of survival time of all mice in group (days) }}{\text { total number of mice in that group }} \text {. }
$$

2.6.6. Measurement of Packed Cell Volume (PCV). PCV was considered to predict efficacy of the extract against hemolysis due to rising parasite level associated with malaria. Heparincoated capillary tubes were employed for blood collection from the tail of each mouse. Blood-filled tubes (up to $(3 / 4)$ th of the volume) were sealed with sealing clay and then placed in a microhematocrit centrifuge, with the sealed end outwards followed by centrifugation for five minutes at $11,000 \mathrm{rpm}$. Finally, tubes were removed from the centrifuge and PCV was evaluated via a standard microhematocrit reader. PCV, a measure of the proportion of RBCs to plasma, was measured prior to inoculation with the parasite and at day four.

$$
\begin{aligned}
& \text { PCV } \\
& =\left(\frac{\text { volume of erythrocytes in a given volume of blood }}{\text { total blood volume }}\right) \\
& \quad \times 100 \% .
\end{aligned}
$$

2.6.7. Monitoring of Body Weight and Temperature Changes. To examine whether the extract prevented weight loss or not, body weight of each mouse was determined in both the suppressive and curative tests. Weights were recorded on day zero (D0) and day five (D4). Rectal temperature was measured by a digital thermometer ahead of infection 4 hours following infection and then on a daily basis. For the curative test, body weight and temperature of the study mice were measured before infection and after infection (from day 3 to day 7).

2.7. Statistical Analysis. The raw data acquired from the experiment was expressed as mean \pm SEM and analyzed using SPSS version 20. Statistical significance was determined via one-way analysis of variance (ANOVA) followed by post hoc Tukey's multiple comparison test. Result was considered significant at $p$ value $<0.05$.

\section{Results}

3.1. Preliminary Phytochemical Assay. Phytochemical screening of the hydroalcoholic crude stem bark extract of $P$. linearifolia revealed the presence of alkaloids, saponins, phenolic compounds, tannins, and terpenoids. On the contrary, flavonoids were absent in the extract (Table 1).
TABLE 1: Phytochemical screening results of stem bark of $P$. linearifolia.

\begin{tabular}{lc}
\hline Phytochemicals & Results \\
\hline Alkaloids & + \\
Saponins & + \\
Terpenoids & + \\
Flavonoids & - \\
Phenols & + \\
Tannins & + \\
\hline
\end{tabular}

+: present, - : absent.

3.2. Acute Toxicity Study. As shown from the acute oral toxicity study, the extract caused no death of mice at the limit dose ( $2 \mathrm{~g} / \mathrm{kg}$ single dose) within the first 24 hours as well as for the subsequent 14 days. Physical and behavioral observations of the experimental mice also discovered no visible signs of toxicity like lacrimation, decrease in appetite, tremors, hair erection, diarrhea, and salivation. This may indicate that the oral $\mathrm{LD}_{50}$ of $P$. linearifolia crude extract is higher than $2 \mathrm{~g} / \mathrm{kg}$.

\subsection{Antimalarial Activity}

3.3.1. Four-Day Suppressive Test. The results of the study showed that $P$. linearifolia crude extract displayed a significant decrease in parasite count compared to that of the vehicletreated mice. In addition, it is important to note that the extract dose-dependently suppressed the malaria parasite significantly at all tested doses (200 and $400 \mathrm{mg} / \mathrm{kg}(p<0.05)$ and $600 \mathrm{mg} / \mathrm{kg}(p<0.001))$. Moreover, $P$. linearifolia extract at the highest dose used $(600 \mathrm{mg} / \mathrm{kg})$ considerably $(p<0.05)$ improved survival date of the study's mice compared to that of the vehicle-treated groups. This effect was much lower than the standard drug (chloroquine $25 \mathrm{mg} / \mathrm{kg}$ ) that markedly ( $p<$ 0.001 ) prolonged survival date of mice (the complete data is presented in Table 2).

\subsubsection{Effect on Rectal Temperature and Body Weight Change} in the Suppressive Test. The extract at the highest dose $(600 \mathrm{mg} / \mathrm{kg})$ caused a significant $(p<0.05)$ decrease in rectal temperature of $P$. berghei-infected mice. Likewise, the standard drug (chloroquine $25 \mathrm{mg} / \mathrm{kg}$ ) showed a considerable $(p<0.001)$ attenuation in reduction of rectal temperature in the study's mice. The standard drug (chloroquine $25 \mathrm{mg} / \mathrm{kg}$ ) extensively $(p<0.001)$ prevented malaria-associated body weight loss. In contrast, the extract was unsuccessful in preventing reduction in body weight of mice at all tested doses (Table 3).

3.3.3. Effect of Crude Extract on Packed Cell Volume (PCV) in the Suppressive Test. The crude extract at 400 and $600 \mathrm{mg} / \mathrm{kg}$ significantly ( $p<0.05$ and $p<0.01$, resp.) prevented reduction in PCV compared to that of the vehicle-treated mice. However, the effect was lower than chloroquine $25 \mathrm{mg} / \mathrm{kg}$ $(p<0.001)$ (Table 4). 
TABLE 2: Effects of $P$. linearifolia stem bark extract on early infection.

\begin{tabular}{lcccc}
\hline Treatment group & Dose & Parasitemia & \% suppression & Survival time \\
\hline & $200 \mathrm{mg} / \mathrm{kg}$ & $24.57 \pm 3.29^{\mathrm{a} 1, \mathrm{~b} 3}$ & $38.17 \pm 8.28$ & $8.60 \pm 0.67$ \\
P. linearifolia extract & $400 \mathrm{mg} / \mathrm{kg}$ & $22.52 \pm 3.40^{\mathrm{a} 1 \mathrm{~b}, \mathrm{~b}}$ & $43.33 \pm 8.56$ & $11.60 \pm 2.56$ \\
& $600 \mathrm{mg} / \mathrm{kg}$ & $17.10 \pm 2.88^{\mathrm{a} 3 \mathrm{~b} 1}$ & $56.98 \pm 7.25$ & $16.4 \pm 4.20^{\mathrm{a} 1, \mathrm{~b} 2}$ \\
Distilled water & $10 \mathrm{ml} / \mathrm{kg}$ & $39.74 \pm 4.99$ & - & $6.80 \pm 0.37$ \\
Chloroquine & $25 \mathrm{mg} / \mathrm{kg}$ & $0.00 \pm 0.00^{\mathrm{a} 3}$ & $100.00 \pm 0.00$ & $30.00 \pm 0.00^{\mathrm{a} 3}$ \\
\hline
\end{tabular}

Data are expressed as mean \pm SEM; $n=5 ;{ }^{\mathrm{a}}$ compared to vehicle (distilled water), ${ }^{\mathrm{b}}$ compared to chloroquine $(25 \mathrm{mg} / \mathrm{kg}),{ }^{1} p<0.05,{ }^{2} p<0.01$, and ${ }^{3} p<$ 0.001 .

TABLE 3: Rectal temperature and body weight change of infected mice treated with P. linearifolia extract in the suppressive test.

\begin{tabular}{lccccccc}
\hline \multirow{2}{*}{ Extract } & \multirow{2}{*}{ Dose } & \multicolumn{3}{c}{ Temperature $\left({ }^{\circ} \mathrm{C}\right)$} & \multicolumn{3}{c}{ Weight } \\
& & D0 & D4 & \% Change & D0 & -7.15 \\
\hline & 200 & $37.18 \pm 0.32$ & $36.46 \pm 0.2$ & -1.93 & $28.8 \pm 1.11$ & $26.74 \pm 0.92$ & D change \\
Extract $(\mathrm{mg} / \mathrm{kg})$ & 400 & $37.68 \pm 0.05$ & $37.04 \pm 0.16$ & -1.69 & $27.72 \pm 1.00$ & $25.76 \pm 1.20$ & -7.07 \\
& 600 & $37.58 \pm 0.09$ & $37.20 \pm 0.11$ & $-1.01^{\mathrm{a} 1}$ & $26.9 \pm 1.23$ & $24.92 \pm 1.38$ & -7.36 \\
Chloroquine & 25 & $36.76 \pm 0.33$ & $36.9 \pm 0.24$ & $0.38^{\mathrm{a} 3}$ & $27.52 \pm 1.70$ & $27.38 \pm 1.42$ & $-0.50^{\mathrm{a} 2}$ \\
Distilled water & $10 \mathrm{ml}$ & $36.76 \pm 0.22$ & $35.16 \pm 0.29$ & -4.35 & $30.42 \pm 0.72$ & $26.56 \pm 0.89$ & -12.68 \\
\hline
\end{tabular}

Data are expressed as mean \pm SEM; $n=5 ;{ }^{\text {a }}$ compared to distilled water treated group, ${ }^{1} p<0.05,{ }^{2} p<0.01$, and ${ }^{3} p<0.001$. D0: value before treatment on day 0; D4: value after treatment on day four.

TABLE 4: PCV of P. linearifolia-treated mice during the 4-day suppressive test.

\begin{tabular}{lccc}
\hline Extract & PCV0 & PCV4 & \% change \\
\hline D/water 10 ml/kg & $53 \pm 0.44$ & $47.4 \pm 0.59$ & $-10.56 \pm 0.59$ \\
Chloroquine 25 mg/kg & $50.8 \pm 0.65$ & $48.8 \pm 0.25$ & $-3.93 \pm 0.25^{\text {a3 }}$ \\
PL200 mg/kg & $51 \pm 0.66$ & $46.8 \pm 0.32$ & $-8.23 \pm 0.32^{\text {b2 }}$ \\
PL400 mg/kg & $52 \pm 0.46$ & $48.4 \pm 0.21$ & $-6.92 \pm 0.21^{\text {a1 }}$ \\
PL600 mg/kg & $52.4 \pm 0.83$ & $49.4 \pm 0.30$ & $-5.72 \pm 0.30^{\text {a2 }}$ \\
\hline
\end{tabular}

Data are expressed as mean \pm SEM; $n=5 ;{ }^{\text {a }}$ compared to distilled water treated group, ${ }^{b}$ compared to chloroquine $25 \mathrm{mg} / \mathrm{kg},{ }^{1} p<0.05,{ }^{2} p<0.01$, and ${ }^{3} p<$ 0.001. PCV0: pretreatment value on day 0; PCV4: posttreatment value on day four; PL: crude extract of P. linearifolia; PCV: packed cell volume.

Table 5: Parasitaemia and survival date of infected mice treated with P. linearifolia extract in Rane's test.

\begin{tabular}{|c|c|c|c|c|c|c|c|}
\hline \multirow{2}{*}{ Dose } & \multicolumn{5}{|c|}{ Parasitemia level } & \multirow{2}{*}{$\%$ inhibition } & \multirow{2}{*}{ Survival time } \\
\hline & Day 3 & Day 4 & Day 5 & Day 6 & Day 7 & & \\
\hline PL200 & $10.08 \pm 2.06$ & $28.74 \pm 5.56$ & $49.36 \pm 5.90$ & $53.99 \pm 5.74$ & $61.25 \pm 8.87^{\mathrm{b} 2}$ & $22.22 \pm 11.26$ & $8.40 \pm 0.50^{\mathrm{b} 2}$ \\
\hline PL400 & $11.01 \pm 1.80$ & $34.01 \pm 3.90$ & $47.60 \pm 2.01$ & $56.47 \pm 3.52$ & $64.28 \pm 2.66^{\mathrm{b} 2}$ & $18.37 \pm 3.38$ & $8.80 \pm 0.66^{\mathrm{b} 2}$ \\
\hline PL600 & $8.64 \pm 1.41$ & $25.02 \pm 4.43$ & $36.01 \pm 4.22$ & $38.75 \pm 3.58$ & $41.89 \pm 2.77^{\mathrm{a} 2, \mathrm{~b} 2, \mathrm{cl}}$ & $46.79 \pm 3.52$ & $10.40 \pm 1.36^{\mathrm{b} 2}$ \\
\hline CON. & $11.52 \pm 1.86$ & $37.39 \pm 5.74$ & $61.62 \pm 6.87$ & $66.96 \pm 5.70$ & $78.75 \pm 5.60$ & - & $7.60 \pm 0.24$ \\
\hline CQ25 & $9.56 \pm 3.04$ & $9.41 \pm 3.71$ & $1.10 \pm 0.40$ & $0.32 \pm 0.23$ & $0.00 \pm 0.00^{\mathrm{a} 2}$ & $100.00 \pm 0.00$ & $30.00 \pm 0.00^{\mathrm{a} 2}$ \\
\hline
\end{tabular}

Data are expressed as mean \pm SEM; $n=5$; ${ }^{a}$ compared to negative control (distilled water), ${ }^{b}$ to CQ, and ${ }^{c}$ to PL400. ${ }^{1} p<0.05$ and ${ }^{2} p<0.001$. CQ: chloroquine; CON: negative control; PL: crude extract of P. linearifolia. Numbers refer to doses used in $\mathrm{mg} / \mathrm{kg}$.

3.3.4. Effect on Established Malaria Infection (Rane's Test). P. linearifolia extract demonstrated a substantial $(p<0.01)$ curative action at the highest dose $(600 \mathrm{mg} / \mathrm{kg})$. Mean parasite count at this dose was $41.89 \pm 2.77$. Even though not comparable to the highest dose, the extract at the lower doses (200 and $400 \mathrm{mg} / \mathrm{kg}$ ) was also capable of decreasing parasite load to $61.25 \pm 8.87$ and $64.28 \pm 2.66$, respectively, while mean parasite count in the untreated control group was $78.75 \pm 5.60$ (Table 5).
Despite the fact that the standard drug (chloroquine $25 \mathrm{mg} / \mathrm{kg}$ ) significantly $(p<0.001)$ prolonged survival date of mice (compared to distilled water treated ones), surviving date of mice was not substantially affected by the test substance at all tested doses (Table 5).

3.3.5. Effect of Extract on Body Weight and Rectal Temperature in Rane's Test. P. linearifolia extract-treated mice at doses of 400 and $600 \mathrm{mg} / \mathrm{kg}$ showed a considerable $(p<0.05)$ 
TABLE 6: Body weight and rectal temperature changes of infected mice treated with P. linearifolia extract in Rane's test.

\begin{tabular}{|c|c|c|c|c|c|c|}
\hline \multirow{2}{*}{ Dose } & \multicolumn{3}{|c|}{ Weight } & \multicolumn{3}{|c|}{ Temperature } \\
\hline & W0 & W4 & $\%$ change & T0 & $\mathrm{T} 4$ & $\%$ change \\
\hline PL200 & $27.90 \pm 1.08$ & $24.74 \pm 0.80$ & $-11.32^{\mathrm{b} 2}$ & $36.98 \pm 0.17$ & $34 \pm 0.46$ & $-7.67^{\mathrm{b} 2}$ \\
\hline PL400 & $27.08 \pm 1.00$ & $23.68 \pm 0.89$ & $-12.55^{\mathrm{b} 2}$ & $36.64 \pm 0.12$ & $34.32 \pm 0.35$ & $-6.33^{\mathrm{a} 1, \mathrm{~b} 1}$ \\
\hline PL600 & $26.92 \pm 1.29$ & $24.62 \pm 0.79$ & $-8.54^{\mathrm{bl}}$ & $37.12 \pm 0.11$ & $34.52 \pm 0.43$ & $-7.00^{\mathrm{a} 1, \mathrm{~b} 2}$ \\
\hline CON. & $27.26 \pm 1.13$ & $23.64 \pm 1.27$ & -13.27 & $36.74 \pm 0.21$ & $32.44 \pm 0.20$ & -11.70 \\
\hline CQ25 & $26.08 \pm 1.20$ & $26.56 \pm 1.39$ & $1.9^{\mathrm{a} 2}$ & $36.64 \pm 0.17$ & $36.22 \pm 0.24$ & $-1.14^{\mathrm{a} 3}$ \\
\hline
\end{tabular}

Data are expressed as mean \pm SEM; $n=5$; ${ }^{\text {a }}$ compared to control; ${ }^{\text {b }}$ compared to CQ; ${ }^{1} p<0.05,{ }^{2} p<0.01$, and ${ }^{3} p<0.001$. CQ: chloroquine; CON: control; PL: crude extract of $P$. linearifolia. Numbers refer to dose in $\mathrm{mg} / \mathrm{kg}$.

TABLE 7: PCV of infected mice treated with crude extract of P. linearifolia in Rane's test.

\begin{tabular}{lccc}
\hline Extract & PCV0 & PCV4 & \% change \\
\hline D/water $10 \mathrm{ml} / \mathrm{kg}$ & $49.8 \pm 0.29$ & $37.2 \pm 1.07$ & $25.3 \pm 2.0$ \\
Chloroquine $25 \mathrm{mg} / \mathrm{kg}$ & $47.4 \pm 0.81$ & $44.4 \pm 0.67$ & $-6.32 \pm 0.70^{\mathrm{a} 3}$ \\
PL $200 \mathrm{mg} / \mathrm{kg}$ & $48.8 \pm 0.51$ & $40.2 \pm 0.43$ & $17.62 \pm 0.59^{\mathrm{b} 1}$ \\
PL $400 \mathrm{mg} / \mathrm{kg}$ & $48.4 \pm 0.60$ & $39.0 \pm 0.40$ & $-19.42 \pm 0.48^{\mathrm{b} 2}$ \\
PL $600 \mathrm{mg} / \mathrm{kg}$ & $51.0 \pm 0.74$ & $44.4 \pm 0.80$ & $-12.94 \pm 0.61^{\mathrm{a} 1}$ \\
\hline
\end{tabular}

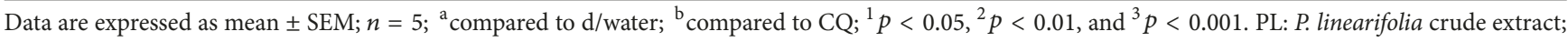
PCV: packed cell volume.

reduction in rectal temperature compared to vehicle-treated mice. This effect was much higher $(p<0.001)$ in mice treated with the standard drug. Even though chloroquine at $25 \mathrm{mg} / \mathrm{kg}$ significantly $(p<0.01)$ prevented weight reduction, the test extract, at all tested doses, was unable to protect mice against weight loss (Table 6).

\subsubsection{Effect of Crude Extract on Packed Cell Volume in Rane's} Test. Only $600 \mathrm{mg} / \mathrm{kg}$ of the crude extract had significantly prevented PCV reduction as compared to vehicle-treated mice $(p<0.05)$ (Table 7$)$.

\section{Discussion}

The in vivo model was preferred for this study because it takes into account the possible prodrug effect and possible contribution of the immune system in eradication of the infection [12]. P. berghei provides an entrenched experimental model of malaria infection [17] causing pathological symptoms that closely mimic symptoms produced by human malaria [18].

Even though the rodent malaria is not exactly similar to that of the human Plasmodium parasites, it is the first step to screen most in vivo antimalarial activities of test compounds $[13,14]$. Moreover, several of the currently available antimalarial medications (chloroquine, halofantrine, mefloquine, and artemisinin derivatives) have been identified by employing this model [19].

The 4-day suppressive test, which chiefly evaluates the activity of potential antimalarial agents on early malaria infection, and Rane's test, which estimates the curative ability of the test compound on established infection, are the two universally accepted methods in screening of compounds with potential antimalarial activity. In both methods, determination of percent inhibition of parasitemia is the most reliable parameter $[13,14,16]$.

It is important to note that percentage parasitemia calculated (from the 4-day suppressive test) revealed the antiplasmodial effect of the extract as shown by the ability of the extract in reducing parasitemia of $P$. berghei-infected mice in a dose-dependent fashion. This may indicate that the plant contains active compounds against the malaria parasite. This antiplasmodial activity exerted by the extract could be attributed to alkaloids and terpenoids contained in $P$. linearifolia crude extract. Alkaloids, as exemplified by quinine, are well known for their antimalarial activity [20]. Methanolic and chloroform extract of P. linearifolia was reported to possess antiplasmodial activity in vitro [9]. This substantiates our in vivo finding. Moreover, a number of chemical compounds have been isolated and identified from Periploca genus, such as alpha- and betaamyrin, lupeol, $B$-sitosterol [21], lupene-type triterpenes, and elemane-type sesquiterpenes [21, 22]. In addition, lupeol, $ß-$ amyrin, and $ß$-sitosterol (terpenoids) are well known for their antimalarial activity against both chloroquine-sensitive and resistant strains of $P$. falciparum in vitro [23]. Therefore, the antiplasmodial activity of $P$. linearifolia in the present in vivo study is in agreement with other plants belonging to the same genus. Survival time, in particular at the highest dose, was very much prolonged by the test extract and was associated with a decline in escalated parasitemia level, suggesting its antiplasmodial activity.

Anemia, reduction in body weight, and a decrease in body temperature are typical features of malaria in mice [24]. PCV was calculated to estimate the efficacy of the extract in averting hemolysis due to rising parasitemia level. Basically, the anemia in both human beings and mouse is attributed to the clearance or damage of infected RBCs, coupled with clearance of uninfected RBCs, and inhibition of 
erythropoiesis by the malaria parasite [25]. This necessitates the analysis of packed cell volume that evaluates the efficacy of the test extract in preventing hemolysis.

The extract, in both the 4-day suppressive test (at 400 and $600 \mathrm{mg} / \mathrm{kg}$ ) and Rane's test (at $600 \mathrm{mg} / \mathrm{kg}$ ), substantially prevented reduction in PCV. This reversal of PCV reduction by the test extract may be associated with its ability in reducing parasitemia of infected mice. However, the crude extract was unable to protect mice against weight loss associated with the malaria parasite. This may be due to disturbed metabolic function and hypoglycemia related to malaria infection [26].

Rectal temperature measurements demonstrated that mice were hypothermic particularly in the late infection (Rane's test) with $P$. berghei parasite. Fever is one of the symptoms of malarial infection in humans. On the contrary, $P$. berghei-infected mice were associated with hypothermia rather than pyrexia. In the curative test, the infected mice developed profound hypothermia with rectal temperature falling by as much as $5^{\circ} \mathrm{C}$. This extended hypothermia in mice could be associated with the devastating consequence of the malaria parasite on the host which may result in body heat loss and ultimately death of mice [27]. Malaria parasite also affects host carbohydrate, lipid, and protein metabolism $[28,29]$. Moreover, a decrease in metabolic rate of $P$. bergheiinfected mice accompanied by a corresponding decrease in internal body temperature has been indicated [30]. Therefore, effective antimalarial candidates are likely to prevent the decrease in rectal temperature. As a result, $P$. linearifolia crude extract significantly attenuated the reduction in rectal temperature of mice in contrast to the control (vehicletreated) group.

The extract at the two lower doses $(200 \mathrm{mg} / \mathrm{kg}$ and $400 \mathrm{mg} / \mathrm{kg}$ ) showed variable effect against parasitemia level reduction, that is, the lowest dose $(200 \mathrm{mg} / \mathrm{kg})$, though not statistically significant, and showed parasitemia suppression value higher than mice receiving the $400 \mathrm{mg} / \mathrm{kg}$ of the extract except on day 5. On the contrary, mice receiving $400 \mathrm{mg} / \mathrm{kg}$ of the extract lived longer compared to mice treated with $200 \mathrm{mg} / \mathrm{kg}$ of the test extract. This may be due to lower metabolic rate of mice at doses of $200 \mathrm{mg} / \mathrm{kg}$ than at $400 \mathrm{mg} / \mathrm{kg}$ of the extract (Table 6).

As indicated in the results section of Rane's test, the standard drug (chloroquine $25 \mathrm{mg} / \mathrm{kg}$ ) started parasitemia reduction following the initial dose. However, this effect was demonstrated by the test extract (at $600 \mathrm{mg} / \mathrm{kg}$ ) subsequent to the next dose. By and large, results from Rane's test indicated that the test extract (at $600 \mathrm{mg} / \mathrm{kg}$ dose) might be useful in curing malaria infection. The effectiveness of the extract both during early infection (suppressive activity) and in the established plasmodium infection (Rane's test) may indicate that $P$. linearifolia could be used as a potential source in the discovery of antimalarial agent from plants. Even though the active antimalarial compound is not elucidated so far, the antimalarial activity of $P$. linearifolia could be due to secondary metabolites (alkaloids, terpenoids, and phenolic compounds) present in the plant. These compounds may produce their antiplasmodial effect either singly or in synergy. Alkaloids, terpenoids, and phenolic compounds are known for their antimalarial activity [31-33].
Potential antimalarial agents with more than 30\% suppressive effect on parasitemia which can prolong the survival date of treated mice compared to the control group are often considered effective in standard screening tests [34, 35]. Therefore, the present in vivo antimalarial evaluation, in both the suppressive and curative tests, denotes that $P$. linearifolia is effective in treating malaria.

\section{Conclusion}

From the results of this study, it can be concluded that $P$. linearifolia stem bark extract not only is safe to mice but also has a promising antiplasmodial activity. Moreover, the results in this study illustrate that correlations exist between the traditional claim as antimalarial agent and the earlier in vitro report.

\section{Additional Points}

Recommendation. Further isolation and characterization of the active compound(s) responsible for its antimalarial activity are required. Subacute and chronic toxicity studies need to be further conducted.

\section{Conflicts of Interest}

The authors declare that they have no conflicts of interest.

\section{Authors' Contributions}

Wubetu Yihunie Belay collected the plant material, prepared the extract, performed phytochemical screening test, toxicity study, antiplasmodial assay, and data analysis, and drafted the manuscript. Zewdu Birhanu Wubneh coordinated the overall work, assisted in the antimalarial assay, interpreted the data, and prepared the manuscript. Abyot Endale Gurmu assisted in coordination and antimalarial assay and interpreted the data. Finally, all authors read and approved the final manuscript.

\section{Acknowledgments}

University of Gondar is highly acknowledged for allowing material assistance for the study and covering some costs. The authors are also grateful to Amhara Health Bureau for their financial support. Ethiopian Public Health Institute, Addis Ababa, is also greatly acknowledged for providing the malaria parasite. The authors also thank the traditional healer Ato Kassie for his cooperation in providing the antimalarial medicinal plant.

\section{References}

[1] World Health Organization. World Malaria Report 2016. Geneva, Switzerland 2016.

[2] Centers for Disease Control and Prevention, https://www.cdc .gov/malaria/about/biology/ (accessed on June 2017). 
[3] International travel and health http://www.who.int/ith/ diseases/malaria/en/, 2017.

[4] World Health Organization, Guidelines For The Treatment Of Malaria 2015.

[5] W. R. H. M. Ballon, D. Caruca, T. L. Richei, G. Corradin, C. Diggs et al., "Uptake on the clinical development of candidate malaria vaccines," American Journal of Tropical Medicine and Hygiene, vol. 71, pp. 239-47, 2004.

[6] World Health Organisation, Update on RTS,S Malaria Vaccine Implementation Programme; 2017.

[7] Fred Musoke, "Natural products, with antimalarial activity phytochemistry and pharmacognosy," Encyclopedia of Life Support Systems, 2016.

[8] China Cooperative Research Group on Qinghaosu and Its Derivatives as Antimalarials. Chemical studies on qinghaosu (artemisinine). Journal of Traditional Chinese Medicine, 1982.

[9] T. A. Ayuko, R. N. Njau, W. Cornelius, N. Leah, and I. O. Ndiege, "In vitro antiplasmodial activity and toxicity assessment of plant extracts used in traditional malaria therapy in the Lake Victoria Region," Memórias do Instituto Oswaldo Cruz, vol.104, no. 5, pp. 689-694, 2009.

[10] V. W. Yeung, I. M. Hastings, A. J. Mills, and N. J. White, "Antimalarial drug resistance, artemisinin-based combination therapy, and the contribution of modeling to elucidating Policy choices. Am J Trop Med Hyg," Antimalarial drug resistance, pp. 71-179, 2004.

[11] OECD, Test No. 425: Acute Oral Toxicity: Up-and-Down Procedure. Paris: OECD Publishing; 2008.

[12] G. B. P. J. Waako, P. Smith, and P. I. Folb, “The in vitro and in vivo antimalarial activity of Cardiospermum halicacabum and Momordica foetida," Journal of Ethnopharmacology, vol. 99, pp. 43-137, 2005.

[13] D. A. Fidock, P. J. Rosenthal, S. L. Croft, R. Brun, and S. Nwaka, "Antimalarial drug discovery: efficacy models for compound screening," Nature Reviews Drug Discovery, vol. 3, no. 6, pp. 509-520, 2004.

[14] B. S. Kalra, S. Chawla, P. Gupta, and N. Valecha, "Screening of antimalarial drugs: an overview," Indian Journal of Pharmacology, vol. 38, no. 1, pp. 5-12, 2006.

[15] S. B. Christensen and A. Kharazmi, "Antimalarial natural products," in Bioactive Compounds from Natural Sources: Isolation, Characterization and Biological Properties, C. Tringali, Ed., pp. 387-404, Taylor \& Francis, New York, NY, USA, 2001.

[16] J. F. Ryley and W. Peters, "The antimalarial activity of some quinoline esters," Annals of Tropical Medicine and Parasitology, vol. 84, 1995.

[17] J. R. Corbert, The Biochemical Mode of Action of Pesticide, American Press, NY, USA, 2nd edition, 1984.

[18] A. R. M. Syahmi, S. Vijayarathna, S. Sasidharan et al., "Acute oral toxicity and brine shrimp lethality of elaeis guineensis jacq., (oil palm leaf) methanol extract," Molecules, vol. 15, no. 11, pp. 81118121, 2010.

[19] A. A. Madara, J. A. Ajayi, O. A. Salawu, and A. Y. Tijani, "Anti-malarial activity of ethanolic leaf extract of Piliostigma thonningii schum. (Caesalpiniacea) in mice infected with Plasmodium berghei berghei," African Journal of Biotechnology, vol. 9, no. 23, pp. 3475-3480, 2010.

[20] S. Saxena, N. Pant, D. C. Jain, and R. S. Bhakuni, "Antimalarial agents from plant sources," Current Science, vol. 85, no. 9, pp. 1314-1329, 2003.
[21] M. Z. M. Askri, A. M. Bui, B. C. Das, and P. J. Hylands, "Medicinal plants of Tunisia. the structure of periplocadiol, a new elemane-type sesquiterpene isolated from the roots of periploca laevigata," Journal of Natural Products, pp. 52-792, 1989.

[22] G. Mustafa, E. Anis, S. Ahmed et al., "Lupene-type triterpenes from Periploca aphylla," Journal of Natural Products, vol. 63, no. 6, pp. 881-883, 2000.

[23] A. L. Nyangasi, "Characterisation of Antimalarial Compounds from Plants used," in Traditional Health Practices in Lake Victoria basin, Jomo Kenyatta University of Agriculture and Technology, 2009.

[24] Q. S. J. Langhorne and L. A. Sanni, "Mouse Models of BloodStage Malaria infections: Immune Responses and Cytokines Involved in Protection and Pathology," in Malaria Immunology, Karger, 2nd edition, 2002.

[25] G. O. M. Chinchilla, G. Abarca, M. Barrios, and O. Castro, "An in vivo model to study the anti-malaria capacity of plant extracts," Revista de Biologia Tropical, vol. 46, pp. 1-7, 1998.

[26] World Health Organization, World Malaria Report; 2011.

[27] G. Jennings and M. Elia, "Effect of E. coli endotoxin on temperature, oxygen consumption and brown adipose tissue thermogenesis in rats and mice," Bioscience Reports, vol. 7, no. 6, pp. 517-523, 1987.

[28] W. A. Siddiqui and W. Trager, "Free amino-acids of blood plasma and erythrocytes of normal ducks and ducks infected with malarial parasite, plasmodium lophurae," Nature, vol. 214, no. 5092, pp. 1046-1047, 1967.

[29] M. G. N. Angus, K. A. Fletcher, and B. G. Maegraith, "Studies on the lipids of plasmodium knowlesi-infected rhesus monkeys (Macaca mulatto)I: Changes in serum lipids," Annals of Tropical Medicine and Parasitology, vol. 65, no. 2, pp. 135-154, 1971.

[30] H. Briand and W. Peter, "Acute malaria: effects of P. bergheion the metabolic rate of mice," The Ohio Journal of Science, pp. 77189, 1977.

[31] A. B. Oliveira, M. F. Dolabela, F. C. Braga, R. L. Jácome, F. P. Varotti, and M. M. Póvoa, "Plant-derived antimalarial agents: new leads and efficient phythomedicines. Part I. Alkaloids," Anais da Academia Brasileira de Ciências, vol. 81, no. 4, pp. 715740, 2009.

[32] K. J. M. Kaur, T. Kaur, and R. Jain, “Antimalarials from nature," Bioorganic and Medicinal Chemistry, pp. 17-3229, 2009.

[33] A. Ferreira, J. Balla, V. Jeney, G. Balla, and M. P. Soares, "A central role for free heme in the pathogenesis of severe malaria: the missing link," Journal of Molecular Medicine, vol. 86, no. 10, pp. 1097-1111, 2008.

[34] J. R. D. A. Silva, A. D. S. Ramos, M. Machado et al., "A review of antimalarial plants used in traditional medicine in communities in Portuguese-Speaking countries: Brazil, Mozambique, Cape Verde, Guinea-Bissau, São Tomé and Príncipe and Angola," Memórias do Instituto Oswaldo Cruz, vol. 106, supplement 1, pp. 142-158, 2011.

[35] F. T. M. Adugna, W. Taddese, and P. Admasu, "In vivo antimalarial activity of crude extract of aerial part of Artemisia abyssinicaagainst P. bergheiin mice," Glob, no. part of, p. 460, 2014. 


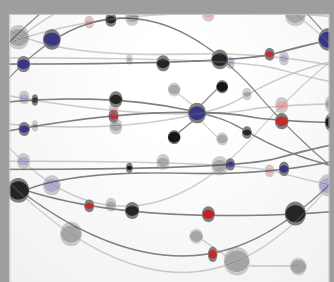

The Scientific World Journal
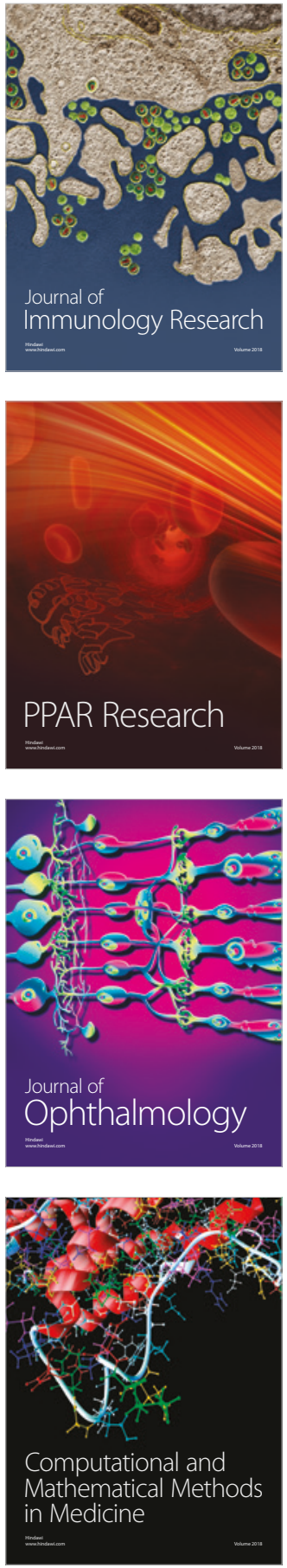

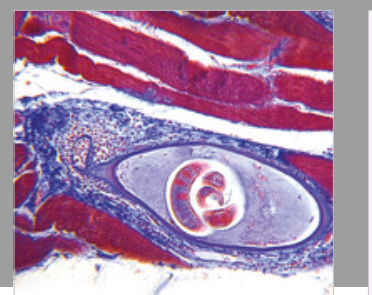

Gastroenterology Research and Practice

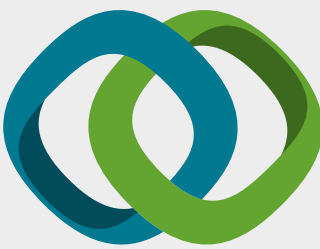

\section{Hindawi}

Submit your manuscripts at

www.hindawi.com
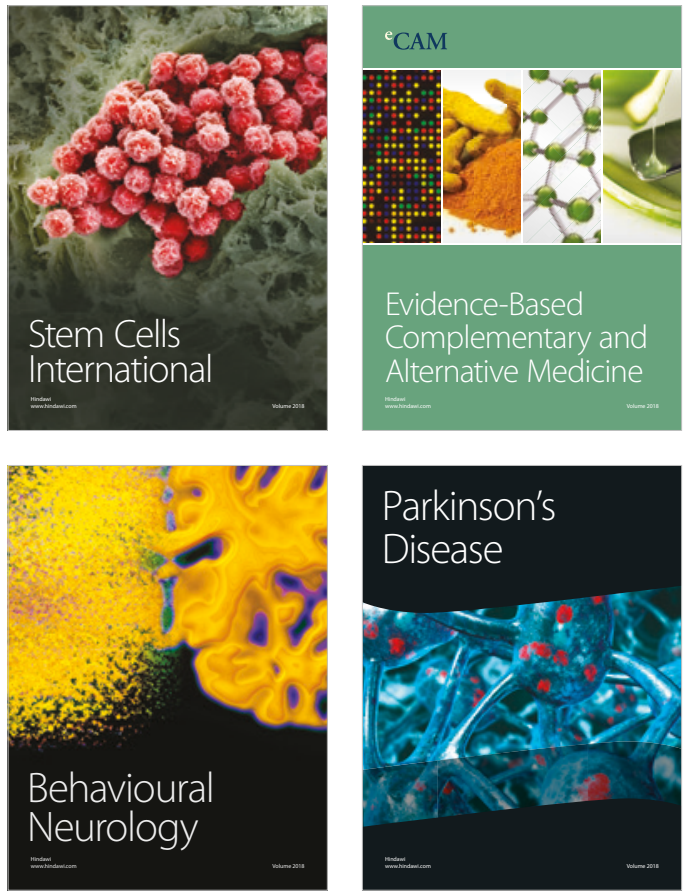

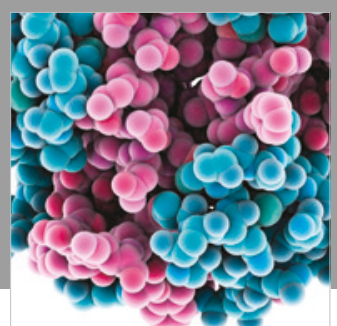

ournal of

Diabetes Research

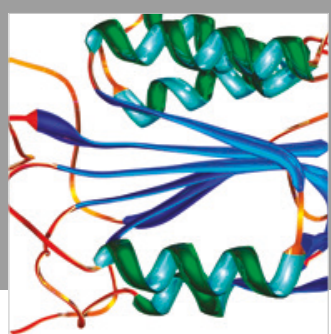

Disease Markers
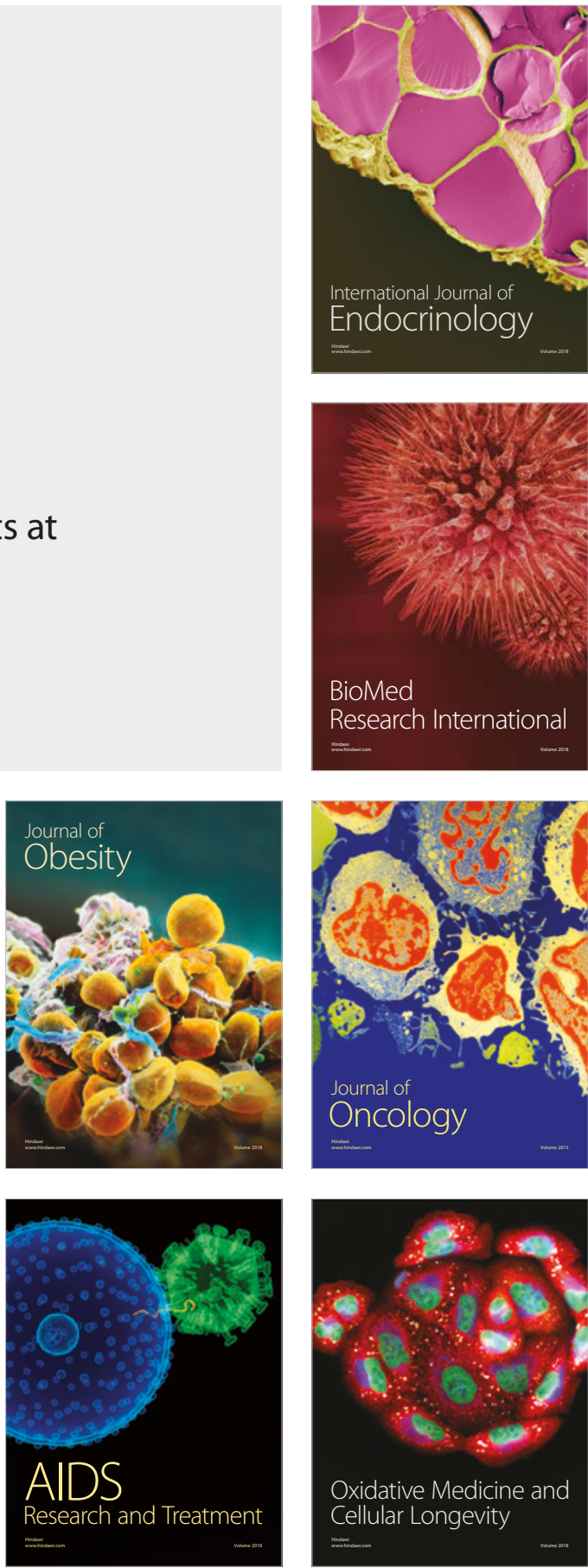